\title{
Trainee Oncologists Experience of Flexible Nasal Endoscopy in the Head and Neck Clinic
}

\author{
Liam Sutton ${ }^{1 *}$, Muhammad Fawad Ul Qamar ${ }^{2}$, Ketan Shah ${ }^{2}$, Amanda Salisbury ${ }^{2}$ and Jonathan Hughes ${ }^{1,2}$ \\ ${ }^{1}$ Head and Neck Centre, University College London Hospitals NHS Trust, UK \\ ${ }^{2}$ Blenheim Head and Neck Unit, Churchill Hospital, UK
}

Submission: February 26, 2018; Published: March 12, 2018

*Corresponding author: Liam Sutton, Head and Neck Centre, University College London Hospitals NHS Trust, UK, Email: liammsutton@gmail.com

\begin{abstract}
Flexible Nasal Endoscopy (FNE) is an essential tool in the joint head and neck cancer follow up clinic to detect residual/recurrent disease, and is performed by both surgeons and oncologists. No national standard exists for FNE training. We undertook a national survey of oncology trainees to determine their experience of performing FNE in the head and neck clinic. 63\% of respondents reported a lack of confidence in performing the procedure, with $72 \%$ asking for assistance. For the majority of trainees $(62 \%)$ training consisted of mere observation. When asked what training respondents would like, there was a preference for locally delivered observation and supervision, with interest in simulation training. It is our belief that FNE training for oncology trainees can be improved with locally delivered competency frameworks.
\end{abstract}

Keywords: Oncology; Head and neck; Endoscopy; Training; Clinic

\section{Introduction}

Flexible Nasal Endoscopy (FNE) is an essential diagnostic tool for the diagnosis and monitoring of head and neck cancers. In the 1980s FNE replaced indirect laryngoscopy (IDL), which relied on an angled mirror placed in the patient's oropharynx and a head-mounted light source. IDL is a difficult procedure, especially in a patient with a prominent gag reflex, and was frequently not tolerated, requiring inspection under general anaesthesia [1]. Conversely, FNE is a relatively easy technique to master, well tolerated by patients and able to deliver excellent recordable images [1]. There is evidence that medical students can become competent at FNE after six supervised procedures on a mannequin [2]. ENT trainees begin using FNE as foundation doctors with supervision from more senior trainees. They may also attend "introduction to ENT courses" where they have the chance to practice in a supervised setting [3].

FNE is also used for the evaluation of non-malignant upper aero-digestive tract disease, and is therefore often used by ENT trainees several times a day, allowing rapid acquisition of proficiency with this technique. Oncologists in most head and neck units also contribute, in conjunction with the surgical team, to joint follow up clinics in reviewing post-treatment patients. Complete and thorough examination of these patients, including endoscopic assessment, is of the utmost importance to detect residual disease, recurrent disease, new upper aerodigestive tract primaries and complications of treatment. Oncology trainees typically rotate through regional specialties, spending
4-6 months per specialty. After a period of observation in clinics, trainees would typically review patients independently and ask for help with patient management if required.

FNE is a unique procedure when compared to other examination techniques employed in oncology clinics as it is relatively technical and perhaps draws on skills not normally selected for in oncology trainees. There are no other cancer clinics, outside the head and neck sub-specialty, where oncologists would perform endoscopic examinations of patients. Furthermore for some future head and neck consultant oncologists a 4-6 month experience of FNE during their head and neck rotation may be all they have before taking a consultant position. There are no standards for FNE training and appraisal during ENT or oncology training. Also there are no assessments of competence in performing the procedure in either the FRCS/ FRCR exit examinations.

\section{Objectives}

We undertook a national survey to gauge the opinions of oncology trainees regarding the use of FNE in the head and neck clinic. We sort to assess the confidence in performing the procedure, how often they ask for help, what training/appraisal they received and what problems they have encountered.

\section{Materials and Methods}

An internet-based survey was designed using SurveyMonkey®software (www. surverymoney.com). The 


\section{Global Journal of Otolaryngology}

survey consisted of nine questions regarding trainee experience of FNE, confidence and problems encountered in performing FNE, training/appraisal received and ideal FNE training model
(Table 1). The survey link was emailed to 236 oncology trainees in the UK from the MSc Oncology course conducted by the Institute of Cancer Research, UK.

Table 1: National Flexible Nasendoscopy Survey: Questions asked to oncology trainees.

\begin{tabular}{|c|c|c|}
\hline \multicolumn{2}{|r|}{ Question } & \multirow{2}{*}{$\begin{array}{c}\text { Possible response } \\
\text { ST3/ST4/ST5/ST6/ST7/Fellow/Other }\end{array}$} \\
\hline 1. & What is your year of training? & \\
\hline 2. & $\begin{array}{l}\text { Have you done a head and neck rotation or are you } \\
\text { currently doing one - please ignore this survey if you } \\
\text { haven't done one yet }\end{array}$ & Yes/no \\
\hline 3. & $\begin{array}{l}\text { How much do you agree with this statement: "I } \\
\text { feel confident doing the flexible nasal endoscopy } \\
\text { procedure in the Head and Neck clinic"? }\end{array}$ & Strongly disagree/ disagree/ undecided/ agree/ strongly agree \\
\hline 4. & $\begin{array}{l}\text { How often do you ask for help with flexible nasal } \\
\text { endoscopy in the Head and Neck clinic? }\end{array}$ & $\begin{array}{l}\text { Never/ rarely - once a month/ sometimes - once a week/ often - most } \\
\text { clinics / frequently - each patient I scope I ask for help }\end{array}$ \\
\hline 5. & $\begin{array}{l}\text { What problems have you encountered whilst doing } \\
\text { flexible nasal endoscopy: }\end{array}$ & $\begin{array}{l}\text { Difficulty handling scope/ Difficulty passing scope through the nose/ } \\
\text { Difficulty entering the oropharynx/ Difficulty in getting a good view } \\
\text { of the larynx/ Difficulty in getting a good view of the hypopharynx/ } \\
\text { Identifying cancer on endoscopy/ Determining the extent of cancer } \\
\text { and anatomical areas involved for treatment planning }\end{array}$ \\
\hline 6. & $\begin{array}{l}\text { What flexible nasal endoscopy instruction have you } \\
\text { received? }\end{array}$ & $\begin{array}{c}\text { Observation of flexible nasal endoscopy/ supervised personal } \\
\text { performance of flexible nasal endoscopy/ Tutorial on flexible nasal } \\
\text { endoscopy procedure/ } \\
\text { Watched a video on flexible nasal endoscopy/Simulation training/ } \\
\text { No training }\end{array}$ \\
\hline 7. & $\begin{array}{l}\text { How much do you agree with this statement: "The } \\
\text { training I received made me feel more confident with } \\
\text { flexible nasal endoscopy in the Head and Neck clinic". }\end{array}$ & strongly disagree/ disagree/ undecided/ agree/ strongly agree \\
\hline 8. & $\begin{array}{l}\text { Have you been appraised formally for flexible nasal } \\
\text { endoscopy competence? }\end{array}$ & Yes/no \\
\hline 9. & $\begin{array}{l}\text { What flexible nasal endoscopy training would you } \\
\text { like? }\end{array}$ & $\begin{array}{l}\text { Local instruction - observation/ Local instruction - observation } \\
\text { and supervision/ Structured local mentorship with observation, } \\
\text { supervision and appraisal/ Elearning with online videos/images/ } \\
\text { National/regional } 1 \text { day course/ Flexible nasal endoscopy training } \\
\text { incorporated into exam revision course/ Simulation training/ other }\end{array}$ \\
\hline
\end{tabular}

\section{Results}

Of the 236 oncology trainees who were emailed with the survey link, 110 replied (46.6\%). 78 trainees (70.9\%) were either currently doing a head and neck oncology rotation or had done one previously during their registrar training. The majority of trainee respondents were ST4 (33\%), ST5 (20\%) and ST6 (20\%). In response to the question, "I feel confident performing the flexible nasal endoscopy procedure in the Head and Neck clinic", 63\% responded "strongly disagree" or "disagree" (Figure 1). $23 \%$ responded "strongly agree" or "agree". When asked "how often do you ask for help with flexible nasal endoscopy in the Head and Neck clinic?", 28\% responded "never". Of the remaining $72 \%$ of trainees who did ask for help in the clinic, $21 \%$ recorded that they ask for help with every patient they see (Figure 2). Table 2 indicates the responses of trainees to the question, "What problems have you encountered whilst performing flexible nasal endoscopy?" $45 \%$ and $30 \%$ of respondents had difficulties achieving adequate views of the hypopharynx and larynx respectively. Difficulties in distinguishing between cancer recurrence and post-treatment changes were noted by $36 \%$ of respondents.

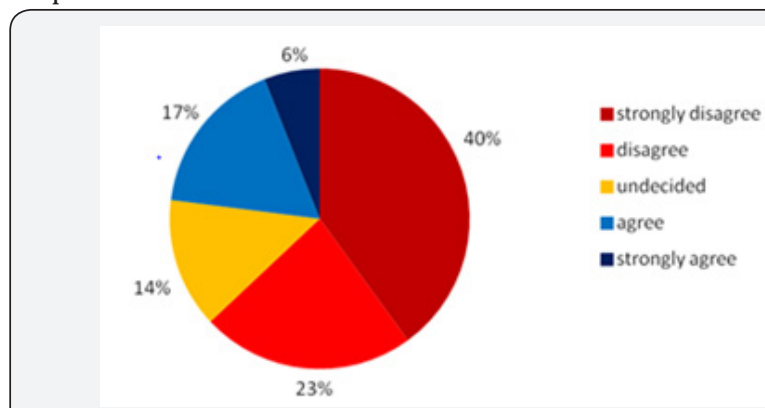

Figure 1: Responses to the question: I feel confident performing the flexible nasendoscopy procedure in the Head and Neck clinic. 


\section{Global Journal of Otolaryngology}

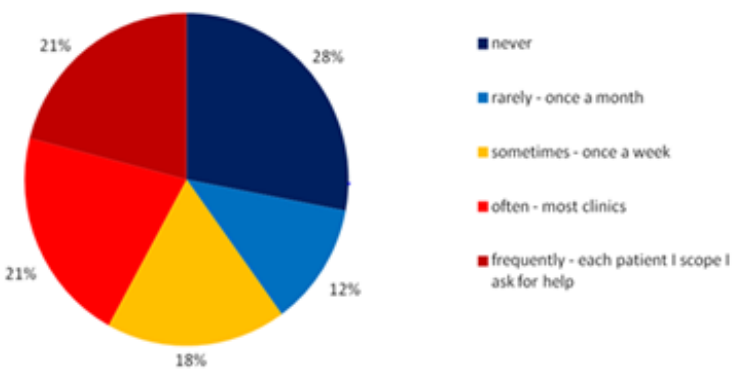

Figure 2: Responses to the question: How often do you ask for help with flexible nasendoscopy in the Head and Neck clinic?

Table 2: Responses to the question: What problems have you encountered whilst performing flexible nasendoscopy?

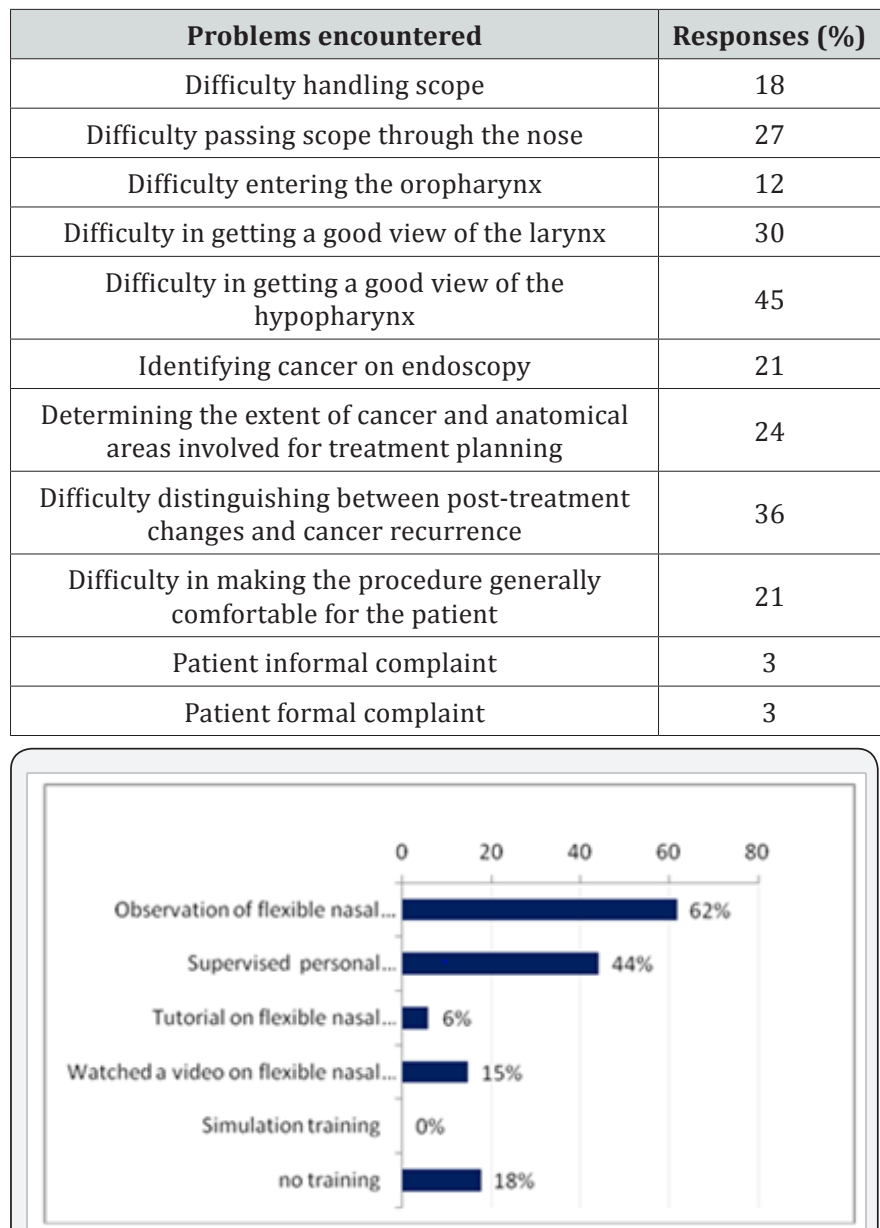

Figure 3: Responses to the question: What flexible nasal endoscopy instruction have you received?

The majority of trainees received observation training of FNE only (62\%). 44\% of respondents had their technique supervised. Few respondents received training that made use of video (15\%) or simulation (0\%) (Figure 3). Responses to the question, "the training I received made me feel more confident with flexible nasal endoscopy in the head and neck clinic" were recorded as $47 \%$ "strongly disagree" or "disagree" and 35\% "strongly agree" and "agree" (Figure 4). 97\% of respondents had received no formal appraisal in flexible nasal endoscopy competence. Finally trainees were questioned as to what endoscopy training they would ideally like to receive to prepare them for the head and neck clinic (Table 3). 56\% favoured local instruction with observation and supervision. $48 \%$ selected a preference for structured local mentorship with observation, supervision and appraisal. 36\% expressed an interest in simulation training.

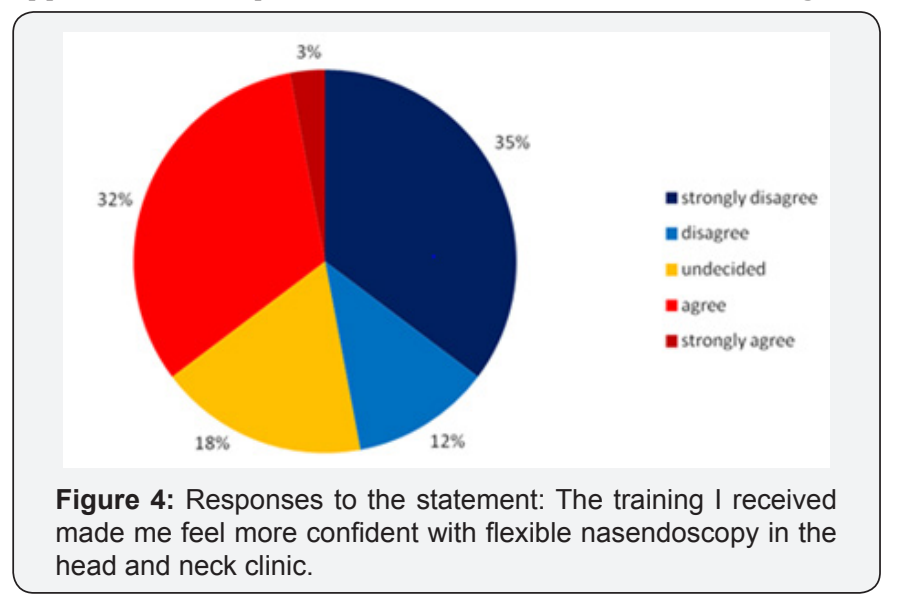

Table 3: Responses to the question: What endoscopy training they would ideally like to receive to prepare them for the head and neck clinic.

\begin{tabular}{|c|c|}
\hline Training option & Response (\%) \\
\hline Local instruction - observation & 9 \\
\hline Local instruction - observation and supervision & 56 \\
\hline $\begin{array}{c}\text { Structured local mentorship with observation, } \\
\text { supervision and appraisal }\end{array}$ & 48 \\
\hline Elearning with online videos/images & 24 \\
\hline National/regional 1 day course & 6 \\
\hline $\begin{array}{c}\text { Flexible nasal endoscopy training incorporated } \\
\text { into exam revision course }\end{array}$ & 36 \\
\hline Simulation training & \\
\hline
\end{tabular}

\section{Discussion}

There is evidence of a $10 \%$ overall rate of suspected cancer recurrence in the head and neck follow up clinic, with glottis the most common area of suspected recurrence (40\%) [4]. Our survey suggested that oncology trainees have experienced high rates of difficulty achieving good views of the hypopharynx (45\%) and larynx (30\%). Difficulties were also reported in differentiating between post-treatment changes and residual disease/recurrence (36\%). Clearly this represents a risk in missed diagnoses of residual and recurrent disease in the posttreatment patients. Delays in treatment of head and neck cancer patients have been demonstrated to result in worse prognostic outcomes [5]. With our evidence of high reported levels of low confidence and uncertainty amongst trainees in performing FNE, the issue is how best to address this. Should all oncology trainees rotating through head and neck be expected to learn and become competent in FNE? Or should this skill become a requirement of the career-head and neck oncology trainee? Should the skill 
be learnt and developed during post-FRCR training or head and neck oncology fellowships?

The alternative would be that oncologist trainees do not learn FNE at all. This would most likely lead to fewer oncology consultants feeling comfortable performing FNE with significant resource consequences for the joint head and neck follow up clinics, where FNE is such a vital tool for cancer surveillance. Furthermore, oncologists may lose the 3D anatomical appreciation of tumours provided by endoscopy that is so vital to radiotherapy planning in the head and neck region. It is our belief that FNE is an important skill for the head and neck oncologist, but that thorough and supportive training is required to ensure it is performed properly to achieve its purpose of identifying residual/recurrent disease allowing prompt salvage treatment. To this end at Oxford we have initiated a local mentorship FNE training programme/competency framework with a period of observation ( $6 \times$ FNEs), then supervised training ( $6 \times$ FNEs), followed by prolonged mentorship with a local digital image/video repository, training video and formal appraisal. This framework could serve as a model for developing FNE competency among UK oncology trainees.

\section{Conclusion}

Our survey suggests widespread lack of confidence amongst oncology trainees in performing FNE in the head and neck clinic
(63\%); with the majority asking for help $(72 \%)$ and $21 \%$ asking for help with every patient they see. $62 \%$ of trainees reported FNE training that consisted of mere observation of the technique, and $44 \%$ had their technique supervised. $47 \%$ of respondents found the FNE training they received was inadequate, with virtually no trainees appraised for competence in this procedure. A preference for locally delivered training was expressed.

\section{References}

1. Lancer JM, Jones AS (1985) Flexible fibreoptic rhinolaryngoscopy. Results of 338 consecutive examinations. The Journal of Laryngology and Otology 99(8): 771-773.

2. Laeeq K, Pandian V, Skinner M, Masood H, Stewart CM, et al. (2010) Learning curve for competency in flexible laryngoscopy. The Laryngoscope 120(10): 1950-1953.

3. Kanegaonkar R, Douse E, Singh S, Vaz F (2005) Benefits of 'An introduction to ENT' for SHO's. Ann R Coll Surg Eng (Suppl) 87: 69.

4. Kothari P, Trinidade A, Hewitt RJ, Singh A, O Flynn P (2011) The followup of patients with head and neck cancer: an analysis of 1,039 patients. European Archives of Otorhinolaryngology 268(8): 1191-1200.

5. Van Harten MC, Hoebers FJ, Kross KW, van Werkhoven ED, van den Brekel MW, et al. (2015) Determinants of treatment waiting times for head and neck cancer in the Netherlands and their relation to survival. Oral Oncology 51(3): 272-278.

Your next submission with Juniper Publishers will reach you the below assets

- Quality Editorial service

- Swift Peer Review

- Reprints availability

- E-prints Service

- Manuscript Podcast for convenient understanding

- Global attainment for your research

- Manuscript accessibility in different formats

( Pdf, E-pub, Full Text, Audio)

- Unceasing customer service

Track the below URL for one-step submission https://juniperpublishers.com/online-submission.php 